\title{
1 Proof-of-concept for a probe to measure pore water pressure 2 in oil-water saturated porous rock
}

\author{
3 Anastasia Capotosto, Bruna de Carvalho Faria Lima Lopes*, Alessandro Tarantino \\ 4 Department of Civil and Environmental Engineering, Faculty of Engineering, University of Strathclyde, 75 Montrose \\ 5 street G1 1 XJ Glasgow - UK \\ 6 *Corresponding author \\ 7 e-mail address: bruna.lopes@strath.ac.uk
}

\section{ABSTRACT}

9 The identification of the Oil/Water Contact (OWC) in a hydrocarbon reservoir is crucial for the determination of its volume and it is also important for detailed petrophysical calculations. Estimation of the OWC requires the determination of the Free Water Level (FWL). Routine practice in the oil and gas industry involves drilling multiple discovery wells since the undulation of the rock layers confining the hydrocarbon reservoir does not generally enable a single discovery well to intercept the water phase. Well drilling is expensive and industry looks forward to approaches to reduce the number of wells required for estimation of the OWC. In this context, this paper presents the proof-of-concept for a probe to measure pore water pressure in oil-water saturated porous rock. This would allow predicting the depth of the FWL in hydrocarbon reservoirs even if the single discovery well does not go through the OWC. This probe could significantly improve the appraisal process and guide the drilling campaigns, saving time, money and reducing the environmental impact of hydrocarbon search. The probe prototype was validated at laboratory scale via measurements of water pressure in core plugs saturated with water and oil. Mock-up tests on sandstone core plugs have shown that the probe can successfully measure water pressure in samples saturated with water and oil as long as the water phase is continuous in the pore space. The paper has therefore provided a proof-of-concept for a technology that can now be moved to the next readiness level. 


\section{INTRODUCTION}

Oil and natural gas originate in petroleum source rocks, which are sedimentary rocks. Natural hydrocarbon reservoirs are composed of layers of porous rocks, called reservoir rocks (generally limestones or sandstones), which are permeated by oil and different pore fluids, such as water (Aminzadeh and Dasgupta, 2013). A natural rock barrier, known as trap, must confine these rocks for a hydrocarbon accumulation to form (Biddle, Kevin and Wielchowsky, 1994). Two different forces control the fluid distribution into the reservoirs: buoyancy and capillary forces (Amyx, Bass and Whiting, 1960). The former causes the lighter fluid (oil) to be positioned in the higher position of the reservoir. The latter causes the intrusion of the wetting fluid (water) by capillary rise into the pore space occupied by the non-wetting fluid. Figure 1a illustrates a schematic representation of a hydrocarbon reservoir in a convex trap created by folding, where DW is a discovery well. The oil, the lighter fluid, is confined under the cap rock whereas water is on the bottom of the hydrocarbon reservoir. Between the two zones, there is an oil-water transition zone where oil and water, often called connate water, are simultaneously present but with different pressure regimes. The thickness of a transition zone may vary from a few centimetres in high-permeability reservoirs to almost $100 \mathrm{~m}$ in low-permeability reservoirs such as carbonate reservoirs, due to its extreme heterogeneity (Shi, Belhaj and Bera, 2018). Considering the oil-water system at a $\mathrm{z}$ depth, the capillary pressure $\mathrm{P}_{\mathrm{c}}$ is defined as the difference between the oil pressure, $\mathrm{P}_{\text {oil }}$, and the water pressure, $\mathrm{P}_{\text {water: }}$ :

$$
P_{c}(z)=P_{\text {oil }}(z)-P_{\text {water }}(z)
$$

This definition of capillary pressure is analogous to that used to define the capillary pressure at the boundary of the water-wet oil reservoir and the cap rock where the two fluid phases are continuous (Teige et al., 2005). The free water level (FWL) is defined as the horizontal plane (depth) where the oil pressure equalizes the water pressure, i.e., where the capillary pressure is zero (Elshahawi, Fathy and Hiekal, 1999). The oil/water contact (OWC) is immediately above the FWL and it is defined as the lowest depth at which mobile oil occurs (Elshahawi, Fathy and Hiekal, 1999). The determination of the OWC is crucial for volumetric calculations of hydrocarbon reservoirs and also important for detailed petrophysical calculations (Arps, 1964; Teige et al., 2005; Niculescu and Ciupercă, 2019).

According to Niculescu and Ciupercă (2019) there are four methods commonly used to define the fluid-contact depths in a wellbore: (i) Mud logs; (ii) Cores; (iii) Resistivity and neutron logs; and (iv) Formation-tester pressure surveys. Usually, the pressure profiles obtained through different formation testing tools are the primary source of data for defining the fluid contacts (Niculescu and Ciupercă, 2019). Thus, the fluid contacts can be determined by identifying the depths at which the pressure gradients change.

In the scenario illustrated in Figure 1a, the FWL can be determined from a single discovery well if the well intersects the FWL. The pressure of the fluid can be measured at different depth along this well and these can be plotted against depth (Elshahawi, Fathy and Hiekal, 1999). The density of both fluids (water and hydrocarbon) is the inclination of the oil and water pressure lines (Underschultz, 2005). Finally, the FWL is the point where the two lines meet $\left(\mathrm{P}_{\mathrm{oil}}=\mathrm{P}_{\text {water }}\right.$ or $\left.\mathrm{P}_{\mathrm{c}}=0\right)$ (Underschultz, 2005), as illustrated in Figure $1 \mathrm{~b}$. Thus, the OWC (and consequently the volume of the reservoir) can be estimated based on the determined depth of the FWL. 


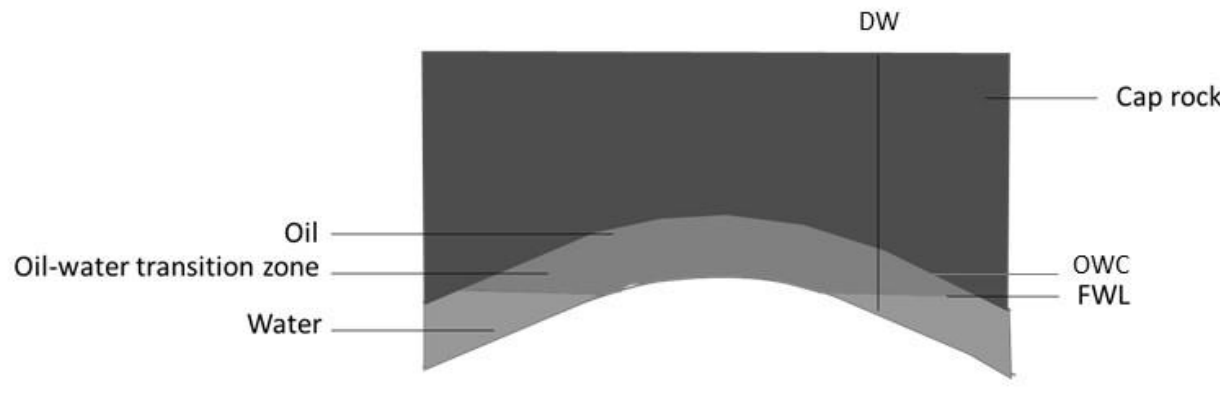

(a)

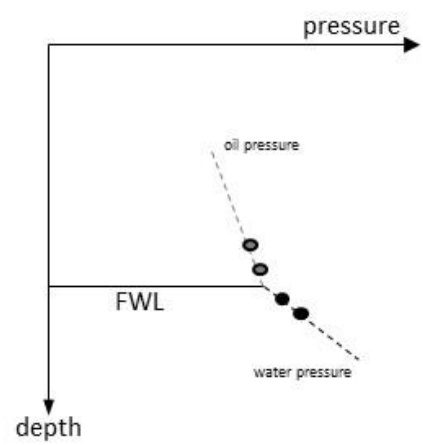

(b)

Figure 1. (a) Typical fluid distribution in a simple convex trap by folding (modified from Amyx, Bass and Whiting, 1960) (b) Current state of the art technology for determining the FWL (modified from Rolfsvåg et al., 2019)

However, several types of trap features, and several combinations of them, can be identified (Amyx, Bass and Whiting, 1960; Biddle, Kevin and Wielchowsky, 1994; Aminzadeh and Dasgupta, 2013) and drilling a single discovery well is not always enough to determine the position of the FWL and hence the OWC (Berg, 1975; Underschultz, 2005). As reported in Rolfsvåg et al. (2019) and Niculescu and Ciupercă (2019) there are some conditions in which the discovery well never intercepts either the OWC or the water due to physical conformation of the rock layers where the hydrocarbon reservoir is confined. In these reservoirs, it is impossible to define the volume of the oil without drilling multiple wells. This is expensive hence it would be ideal if the position of the FWL could be discovered by drilling a single well.

Hydrophilic AS (Tananger, Norway) has devised a technology to predict the depth of the FWL in hydrocarbon reservoirs even if the single discovery well does not go through the FWL. The idea is simple: if the water pressure can be measured inside the oil reservoir above the FWL, the hydrostatic distribution of water pressure can be derived via the unit weight of the water phase. At the same time, if the oil pressure is determined via conventional methods (Amyx, Bass and Whiting, 1960; Vavra, Kaldi and Sneider, 1992) at the same depth, the hydrostatic distribution of oil pressure can be derived via the unit weight of the oil phase. The intersection of the two hydrostatic pressure profiles would allow for the estimation of the depth of the FWL as illustrated in Figure 2. In turn, this would allow estimating the depth of the OWC. The 'single well' methodology could significantly improve the appraisal process and guide the drilling campaigns, saving time, money and reducing the environmental impact of hydrocarbon search. The core of this technology is the measurement of the water pressure above the FWL and the challenge is the measurement of water pressure in porous rock for the case where water and oil are simultaneously present in the porous space.

This paper presents the development of the proof-of-concept for a probe to measure pore water pressure in oilwater saturated porous rock and its validation at the laboratory scale via measurement of water pressure in core plugs saturated with water and oil.

The validation consists in imposing independently oil pressure and water pressure at the two opposite ends of a core plug installed in a multiphase cell. Capillary pressure can be generated by increasing the oil pressure at one end while maintaining the water pressure constant at the other end. The hydrophilic probe is validated if it is shown that it measures the same water pressure imposed at one end regardless of the oil pressure imposed at the other end (under equilibrium conditions).

Previous researchers have developed multiphase cell setups where oil and water pressures were controlled independently. These encompassed applications ranging from investigations of transport and retention of twoand three-phase systems (Busby, Lenhard and Rolston, 1995; Steffy, Barry and Johnston, 1997; Cui, Delage and Alzoghbi, 2003); study of the influence of oil-water suction on the mechanical responses of chalk (De Gennaro et al., 2003); multi-rate water injection tests to measure pressure drop and oil production (Andersen et al., 2019); to experiments that simulate water flow through oil-saturated core plugs (Teige et al., 2005, 
2006). The experimental setup of the multiphase cells developed in these previous works formed the basis for the cell developed in this paper to validate the hydrophilic probe.

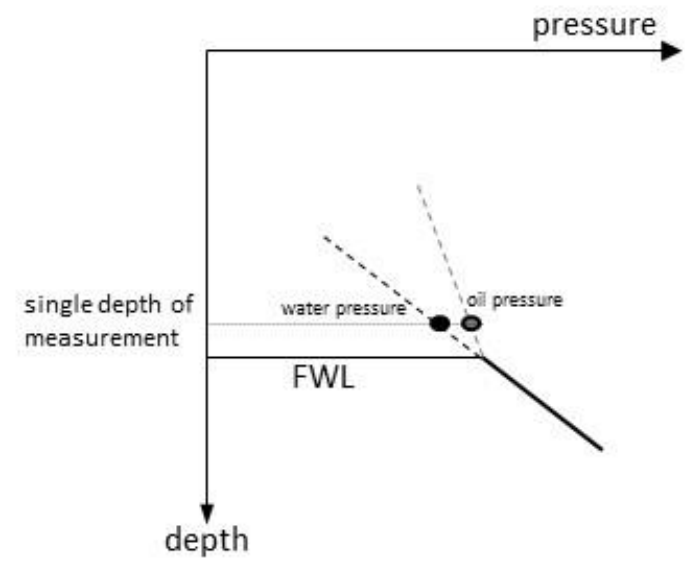

Figure 2. Proposed technique for determining the FWL (modified from Rolfsvåg et al., 2019)

\section{PROBE CONCEPT}

The probe concept is based on the technology developed in the field of unsaturated soil mechanics to measure the pore-water pressure in partially saturated geomaterials, i.e. geomaterials where the fluids occupying the pore space consist of a wetting fluid (water under negative pressure) and a non-wetting fluid (air at atmospheric pressure). To measure the pressure of pore-water (wetting fluid), a ceramic filter is used to allow the water under negative pressure to enter the sensor and, at the same time, to prevent the air at atmospheric pressure (non-wetting fluid) from entering the sensor thus invalidating the measurement (Tarantino, 2004). Air-entry is prevented by the menisci forming at the ceramic filter interface and the maximum air-water pressure differential that can be sustained by the menisci is predicted by the Laplace's equation based on the air-water surface tension $T_{\text {air-water }}$ and the contact angle $\theta$ formed by the menisci at the solid-air-water interface. For the case of a cylindrical pore having diameter $d$, the maximum air-water pressure differential is given by:

$$
P_{\text {air }}-P_{\text {water }}=\frac{4 \cdot T_{\text {air }- \text { water }} \cdot \cos \theta}{d}
$$

In an oil-water system, the measurement of the pore-water pressure (wetting fluid) could be done using a similar concept. In this case, the ceramic interface must be able to allow the water to enter the sensor (hydrophilic sensor) and, at the same time, preventing the ingress of oil (non-wetting fluid) making the sensor oleophobic. The similarity between the air-water and the oil-water pore fluid systems provides the basis to develop the hydrophilic/oleophobic probe. In an oil-water system, the oil behaves as a non-wetting fluid, similarly to the air in the air-water system (Figure 3).
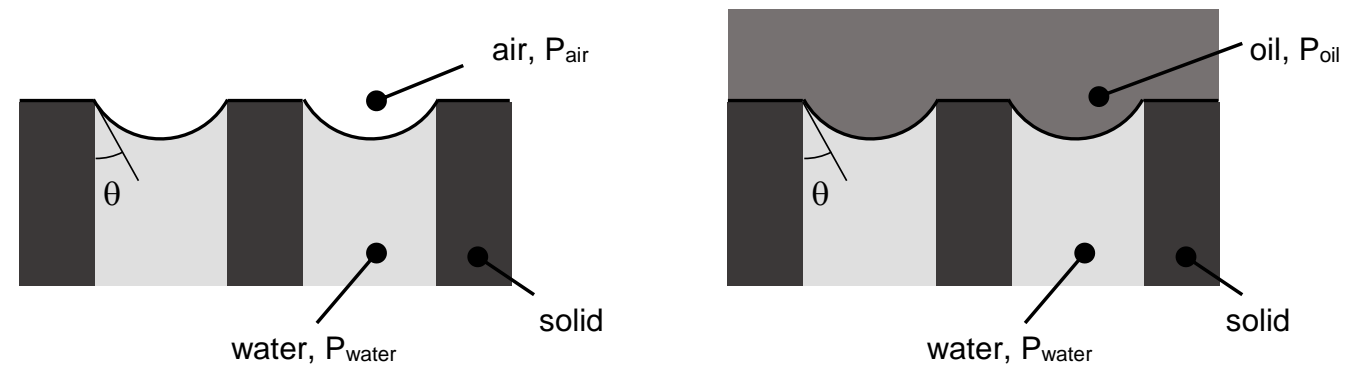

Figure 3. Maximum pressure differential sustained by menisci at the interface between wetting and non-wetting fluid 
A proof of that is provided by a simple experiment using a $1.6 \mathrm{~mm}$ capillary tube (Figure 4). Placing the capillary tube in free water, due to the capillary forces, water rises in the tube forming a concave meniscus at the contact with the air phase, which is the non-wetting fluid in the water/air system (Figure 4a). If the same experiment is repeated using free oil in place of water (refined oil - Isopar), the result is similar (Figure 4b). In this new system, the air still represents the non-wetting fluid. Because of the lower surface tension and the higher contact angle of the oil-air interface (compared with the water-air interface) - capillary rise is lower in the air-oil system.

When oil is placed in contact with water (Figure 4c), the shape of the meniscus at the oil-water interface is concave toward the oil. In the system water/oil, the oil behaves like a non-wetting fluid as air does for water and as air does for oil. As a result, the key to measure the pore-water pressure in an oil-water system is the development of an interface capable of sustaining the oil-water pressure differential due to the menisci forming at the oil-water interface. In other words, the success of the proof-of-concept depends on the development of a high oil-entry pressure ceramic interface. It is expected that the capacity of the porous ceramic filter to sustain the oil-water pressure differential is associated with the oil-water surface tension and the contact angle formed by the menisci at the solid-oil-water interface (in a way similar to the case shown in Figure 3 for air/water system).

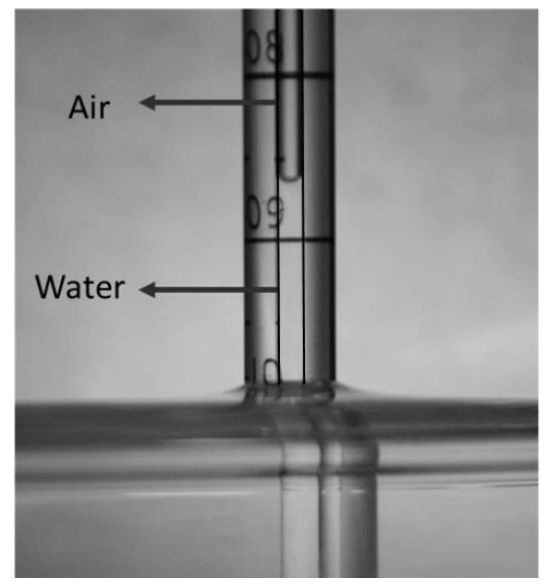

(a)

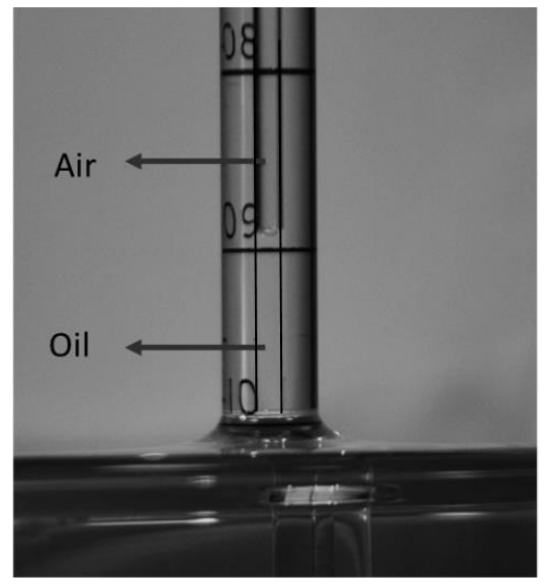

(b)

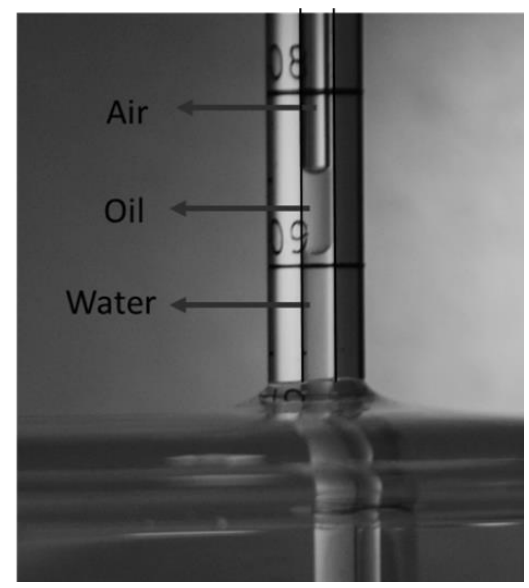

(c)

Figure 4. Wettability. (a) water/air system; (b) Oil/air system; (c) Water/oil/air system

\section{PROBE DESIGN}

\subsection{Assessing the oil-entry pressure of the ceramic filter}

Due to the key role played by the ceramic filter interface, the first experiment was designed to assess the oilentry pressure of the ceramic filter. The device was developed based on the concept of the bubbling-pressure device used to assess the air-entry pressure of water-saturated ceramic filters.

In the traditional bubbling pressure device, a saturated ceramic filter is interposed between two chambers: the bottom chamber is a closed chamber filled with pressurised air whereas the upper chamber is filled with water and open to the atmosphere. The air pressure in the bottom chamber is progressively increased until the air breaks through the menisci formed at the air-water interface and flows through the porous filter, thus generating bubbles in the water in the upper chamber. The air-entry pressure is defined as the pressure associated with the first air bubble appearing on the ceramic surface in the upper chamber.

For the device developed in this research (Figure 5), a water saturated ceramic disk (Soil Moisture, 15 bars porous ceramic) was interposed between two closed chambers. The ceramic disk was initially dried in a desiccator for 48 hours, then it was saturated with deaerated and demineralized water at 4 MPa for 24 hours. Once saturated, it was placed between the two closed chambers (Figure 5). The bottom chamber was filled 
with oil whereas the upper chamber was filled with water. In contrast to the traditional bubbling pressure device, the upper chamber was closed. It was first filled with water at atmospheric pressure through valve B and then valve B was closed once the upper chamber was entirely filled with water. The bottom chamber was connected to an oil/gas interface that in turn was connected to a nitrogen gas bottle. Using the nitrogen bottle pressure regulator, the nitrogen pressure and, hence, the oil pressure could be increased in the bottom chamber. A pressure transducer connected to the bottom chamber (PT1, Figure 5) was used to monitor accurately the oil pressure. The pressure in the water-filled upper chamber was monitored by a second pressure transducer (PT2, Figure 5).

If the saturated porous filter prevents the breakthrough of oil, the pressure in the upper chamber should remain unaffected by the increase of the oil pressure in the bottom chamber. On the other hand, if the menisci at the water-oil interface in the bottom chamber breaks through, the oil should penetrate the upper chamber and the pressure in the upper chamber should increase until equalising the pressure in the bottom chamber.

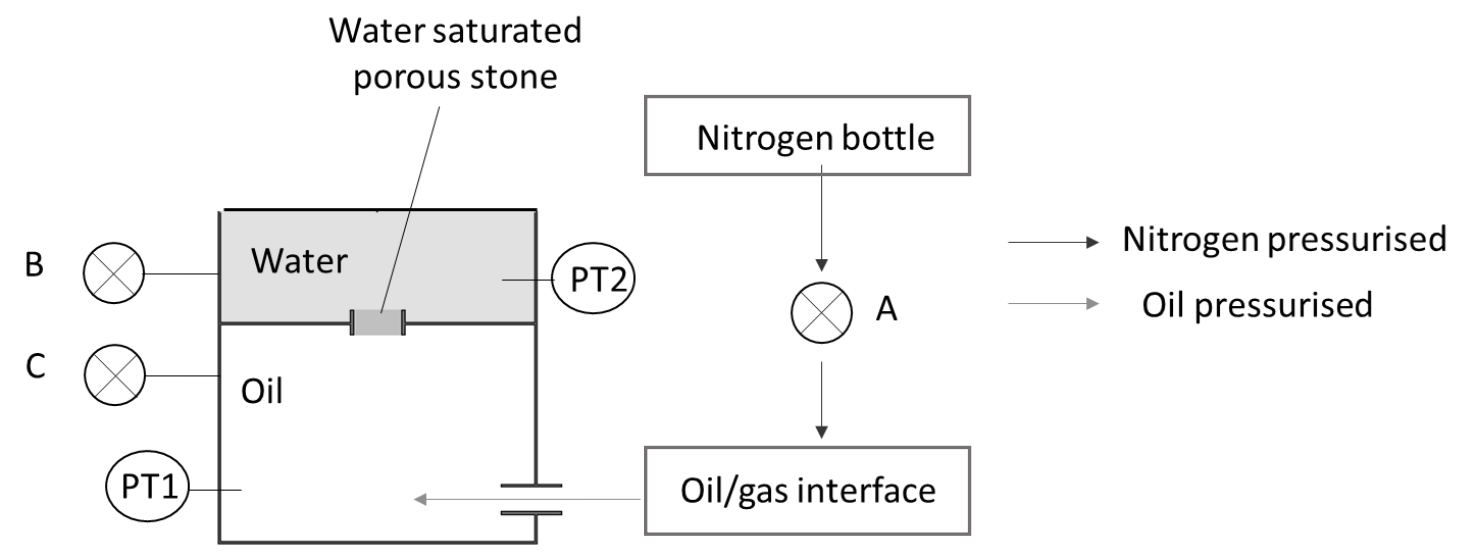

Figure 5. Schematic representation of the modified bubble pressure device

The test was performed in five stages (Table 1). In stage S1, valve A was open, the nitrogen pressure was manually increased in steps of $100 \mathrm{kPa}$ until approximately $600 \mathrm{kPa}$. Through the oil/gas interface, this increase of pressure was fully transferred to the oil in the bottom chamber (Figure 5). Then, the pressure in the oil chamber was maintained constant for about 200 minutes (stage S2). Afterwards, the oil pressure was increased again in steps of approximately $100 \mathrm{kPa}$ every 2 min up to $2,700 \mathrm{kPa}$ (stage S3) and then maintained constant for 20 minutes (stage S4). Finally, valve A was closed and valve $\mathrm{C}$ was open to vent the bottom chamber to the atmosphere (stage S5).

Table 1. Bubbling pressure test: experimental stages sequence

\begin{tabular}{clc}
\hline Stage & \multicolumn{1}{c}{ Description } & Duration \\
\hline S1 & Pressure in the oil chamber increased up to $600 \mathrm{kPa}$ & $50 \mathrm{~min}$ \\
S2 & Pause & $200 \mathrm{~min}$ \\
S3 & Pressure in the oil chamber increased up to 2,700 kPa & $45 \mathrm{~min}$ \\
S4 & Pause & $20 \mathrm{~min}$ \\
S5 & Pressure reduced & - \\
\hline
\end{tabular}

Figure 6a shows the pressure in the bottom (oil) and upper (water) chamber measured by the two transducers. The five stages as per Table 1 are also identified in the figure. Despite the large increase in pressure in the oil chamber (from 0 to $2,700 \mathrm{kPa}$ ), the pressure variation in the water chamber appeared to be negligible. This suggests that the oil never broke through the ceramic filter and that the oil entry pressure is greater than 2,700 $\mathrm{kPa}$.

Nonetheless, it is instructive to observe more closely the pressure variations in the water chamber (Figure 6b). The first change recorded by the pressure transducers occurred after the refilling of the bottom and upper chamber with oil and water respectively and the closure of valves B and C. This generated a small increase in 
pressure of $7 \mathrm{kPa}$ in the bottom oil-filled chamber and a small decrease in pressure of $-2.5 \mathrm{kPa}$ in the upper water saturated chamber.

Upon the first increase in oil pressure up to $600 \mathrm{kPa}$ (stage S1), the pressure in the water chamber remained essentially constant, showing indeed a slight decrease at the end of stage S1. This reduction also continued during the first part of stage S2 but at a lower rate. In the second part of stage S2 the water pressure started rising at almost constant rate despite the fact that the oil pressure was maintained constant. During the third stage, the pressure in the upper chamber started increasing more than linearly until the inflection point $I$. After the inflection point, the pressure in the upper chamber increased at a gradually decreasing rate, even if the oil pressure in the bottom chamber pressure kept increasing.

This can be attributed to the deformation of the menisci at the oil-water interface shown in Figure 3. An increase in pressure differential between oil and water needs to be accommodated by a decrease in the contact angle, i.e. the menisci need to deform towards the water to generate a smaller contact angle. This deformation causes a slight compression of the water and, hence, a slight increase in its pressure. The oil-water-solid junction is also likely to be subject to deferred displacement (creep) and this would explain the time lag between the increase in oil pressure and the increase in water pressure.
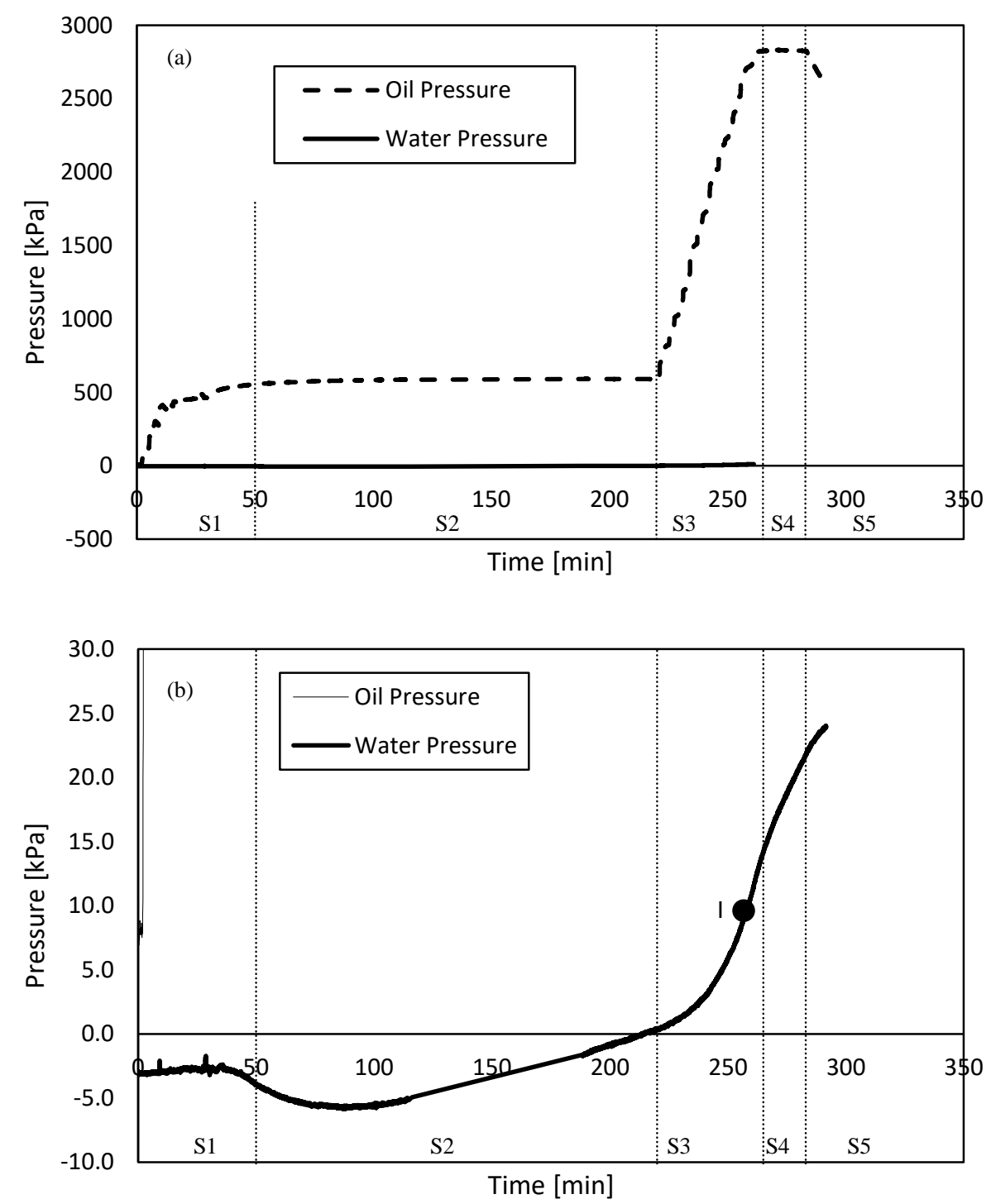
pressure) results. (b) zoom into the water pressure variation, where I is the inflection point, S1 to S5 represent the experimental stage sequences. 


\subsection{Probe assembly}

Once the suitability of the saturated ceramic interface to behave as an oleophobic barrier was checked, a probe was built to measure the pore-water pressure inside a sandstone sample partially saturated with oil. The schematic layout of the probe prototype is shown in Figure 7. It consists of a commercial pressure transducer (Keller Piezo-resistive Pressure Transducer, pressure range 0 to 5 bars, error band of $\pm 0.25 \%$ ) with a male G1/4" pressure port and a brass shroud incorporating the ceramic filter (hydrophilic tip). The ceramic filter was glued using epoxy resin.

The shroud was machined with an inner female thread and screwed onto the pressure transducer. A gap of $1 \mathrm{~mm}$ on the inner side of the shroud was left unthreaded to avoid any damage to the ceramic interface when the tip was screwed onto the transducer pressure port. Before screwing the tip onto the pressure transducer, the ceramic filter was saturated with deaerated and demineralized water for at least 24 hours at $4 \mathrm{MPa}$ by placing the hydrophilic tip in a saturation chamber. To avoid entrapping air bubbles in the $1 \mathrm{~mm}$ gap, the tip and the pressure transducer were assembled under demineralised and deaerated water. An O Ring Washer Seal Gasket was interposed between the shroud and the transducer.

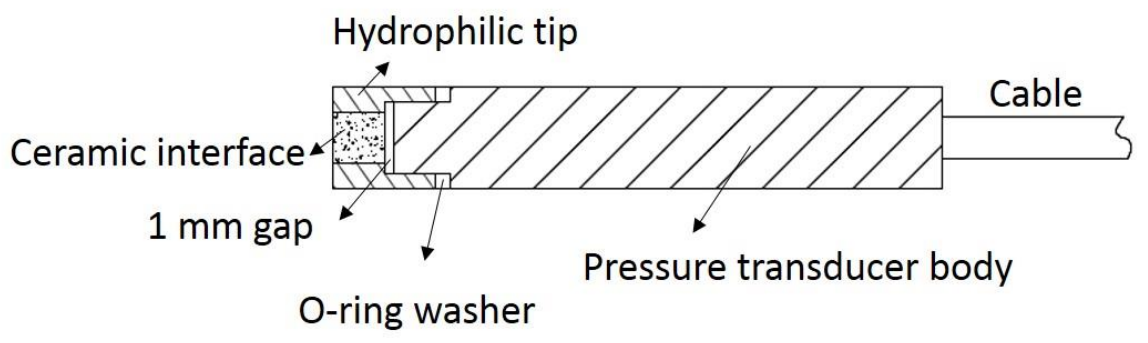

Figure 7. Schematic layout of the hydrophilic probe prototype

\section{EXPERIMENTAL METHODS FOR PROBE VALIDATION}

The response of the probe was validated via two tests in sandstone core plugs partially saturated with water and oil. The experimental procedures are presented in the following sections.

\subsection{Experimental apparatus}

The experiment was designed to measure the pore water pressure in cylindrical sandstone samples (38 $\mathrm{mm}$ diameter, $76 \mathrm{~mm}$ height) partially saturated with water and oil. For this purpose, a conventional triaxial cell was used to impose independently the pore-water and pore-oil pressures (Figure 8). Three pressure lines were used to impose the confining pressure, the pore-water pressure, and the pore-oil pressure respectively. The confining pressure was imposed using pressurised air from the laboratory air supply system and an air/water interface (bladder 1, Figure 8). The pore-water pressure was imposed through the sample pedestal using a pressure/volume controller (GDS 1). A high oil-entry porous ceramic disk was glued into the pedestal to prevent the ingress of oil into the water pressure line. Finally, the oil pressure was applied using a second pressure/volume controller (GDS 2) connected to a water/oil interface (bladder 2, Figure 8). An additional pressure transducer was installed along the oil line after bladder 2 to cross-check the oil pressure imposed via GDS 2 controller. 


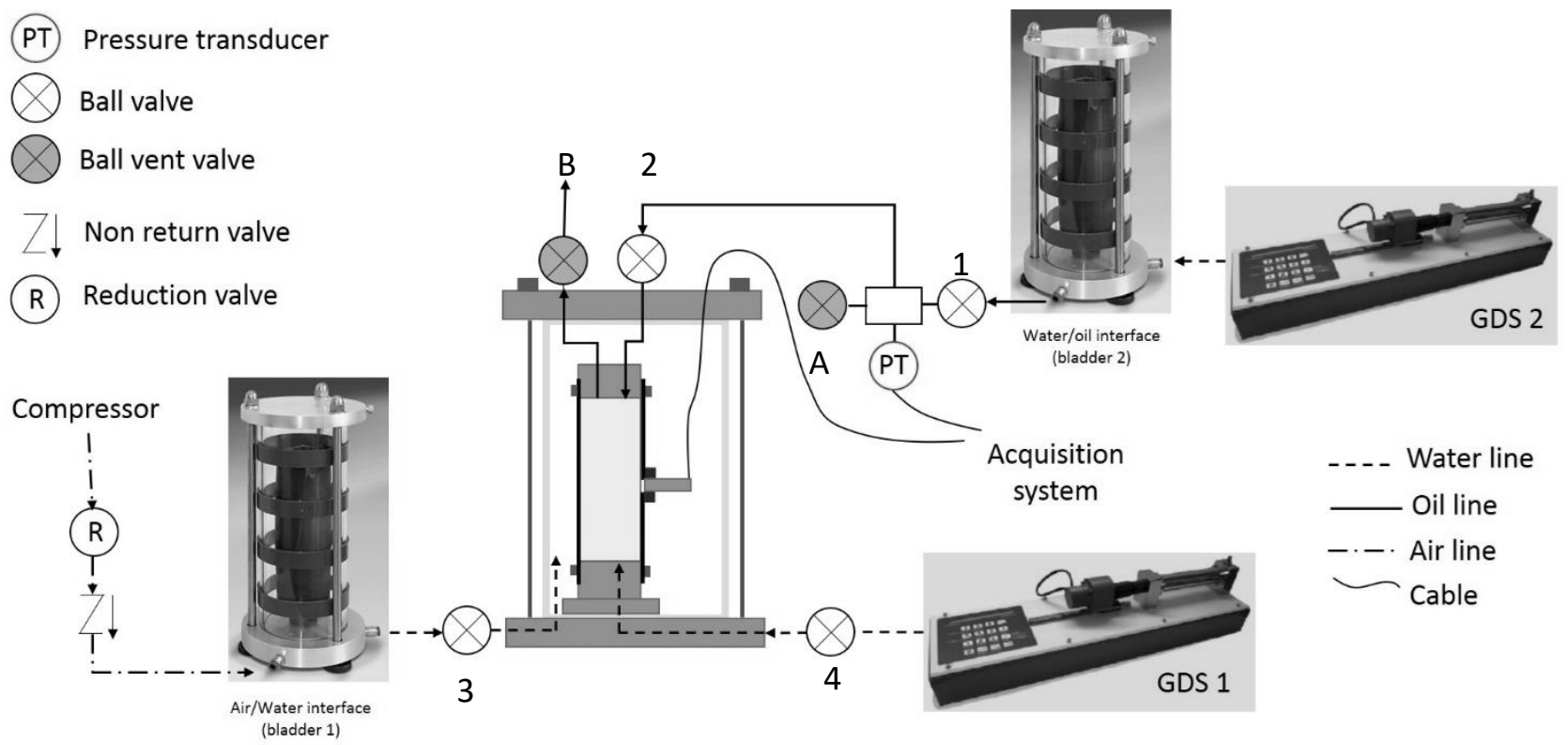

Figure 8. Experimental setup

\subsection{Probe installation}

A shrinkable membrane was used to cover the sample and separate the fluid used to impose the confining pressure from the sandstone pore-fluid. The membrane was fixed to the sample pedestal and top cap using two metallic cable ties. The hydrophilic probe was installed at the sample mid-height through the membrane as shown schematically in Figure 9a. To this end, a rubber adaptor was glued to the membrane using an epoxy resin and a hole was then created through the membrane using a hot tip. The hydrophilic probe was then inserted inside the rubber adaptor and a cable tie on the outer surface of the rubber adaptor was used to improve the contact between the rubber and the probe. The rubber adaptor was manufactured by casting liquid rubber into a purposely designed mould. The inner hole was designed with conical shape to ease the probe insertion and improve the contact with the probe. To ensure the continuity between the water in the probe ceramic filter and the water inside the sample, the conical hole was partially filled with kaolin paste (at a water content of approximately $100 \%$ ). Figure $9 \mathrm{~b}$ shows the system assembled just before the application of the cable tie around the rubber adaptor. 


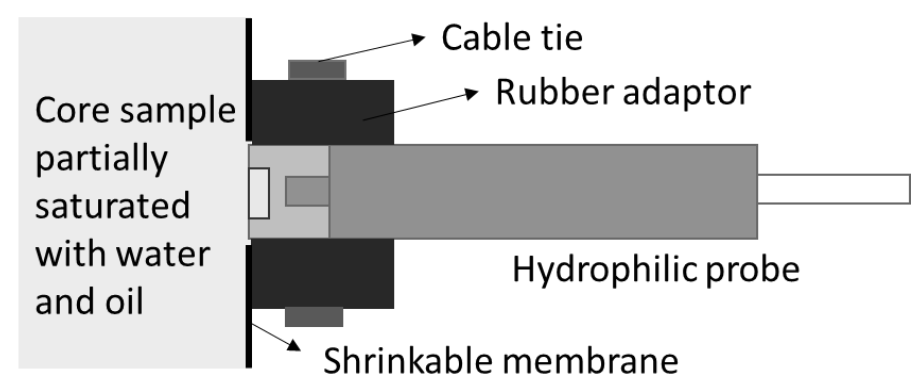

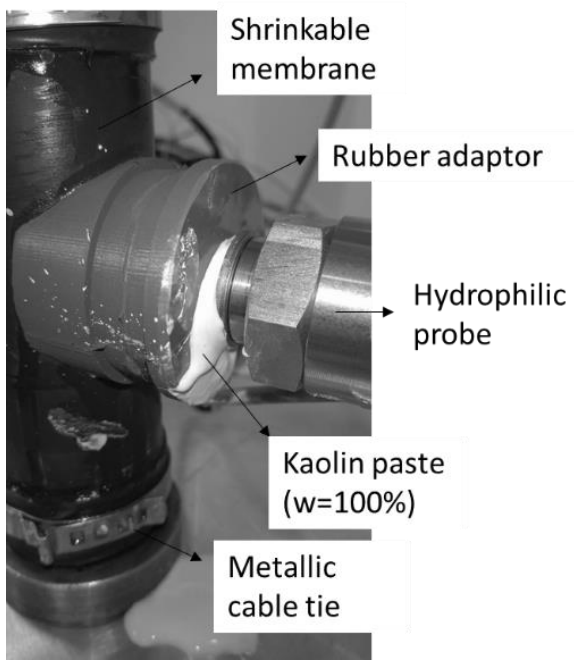

(b)

Figure 9. Hydrophilic probe. (a) Installation scheme. (b) Hydrophilic probe installed on the external surface of the sample

\subsection{Sample saturation}

The samples used in the experimental program were made available partially saturated (with air and water). A procedure was therefore devised to fully saturate the sample with water. Each sample was first oven dried (105 ${ }^{\circ} \mathrm{C}$ for 24 hours) and then two saturation steps were followed.

The sample was placed in a glass beaker which was then placed in the triaxial cell. Vacuum was first applied from vent valve B (Figure 10a). Once a proper value of vacuum (-96 kPa) was reached, valve B was closed and valve 3 was opened to allow gentle ingress of water at the bottom of the cell from a tank containing deaerated and demineralised water. During this process, the water level progressively raised until reaching the beaker rim. Water eventually overflowed into the beaker thus saturating the sample from its bottom (Figure $10 b)$.

After this first phase, water was allowed to fill the entire cell and was then pressurised to $0.6 \mathrm{MPa}$ for at least 24 hours to improve sample saturation. Afterwards, the cell pressure was released, the water in the cell drained out, the cell dismantled, and the beaker containing the submerged sample removed. To install the sample in the triaxial cell (Figure 8), the membrane was initially fixed to the pedestal, the sample was quickly transferred from the beaker to the pedestal to minimise and water loss by evaporation, the membrane was rolled over the sample and the top cap, together with cable ties were set in place to tighten the membrane to pedestal and top cap respectively.

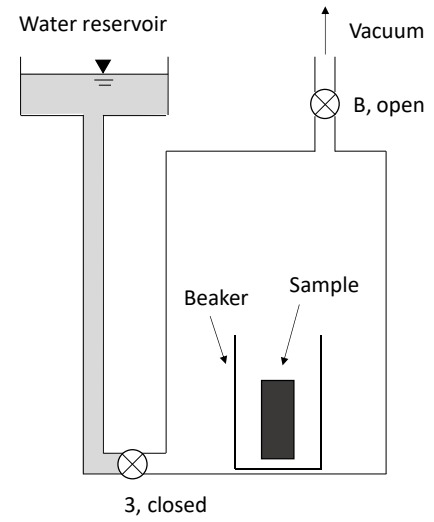

(a)

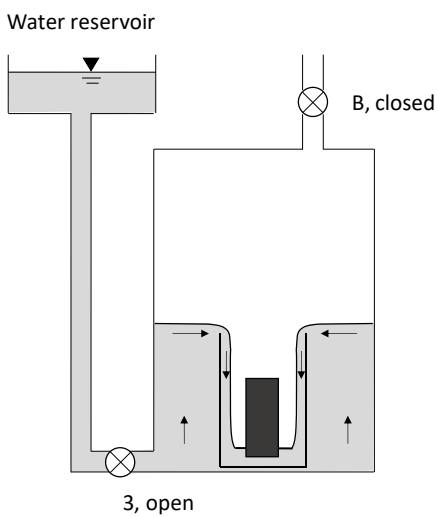

(b) 


\section{RESULTS AND DISCUSSION OF PROBE VALIDATION}

Two tests on different sandstone samples (Table 2) were carried out. The samples were initially fully saturated with water. Oil pressure at the top of the sample was then increased while maintaining constant the water pressure imposed at the bottom of the sample. This generated an increase in the capillary pressure imposed at the ends of the sample that caused the oil to enter the sample by displacing the pore-water. A confining pressure was applied to counterbalance the internal pore-fluid pressures.

These tests were aimed at verifying that water pressure measured by the probe at sample mid-height under equilibrium conditions was controlled by the water pressure imposed at the bottom of the sample, i.e. it was independent of the oil pressure imposed at the top of the sample. In each test, a first preliminary phase, referred to as 'continuity test', was carried out to check the saturation of the system.

Table 2. Characteristics of sandstone samples

\begin{tabular}{cccccccc}
\hline $\begin{array}{c}\text { Sample } \\
\text { identification }\end{array}$ & $\begin{array}{c}\text { Air permeability } \\
{[\mathrm{mD}]}\end{array}$ & $\begin{array}{c}\text { Grain Density } \\
{\left[\mathrm{g} / \mathrm{cm}^{3}\right]}\end{array}$ & $\begin{array}{c}\text { Pore } \\
\text { Volume } \\
{\left[\mathrm{cm}^{3}\right]}\end{array}$ & $\begin{array}{c}\text { Grain Volume } \\
{\left[\mathrm{cm}^{3}\right]}\end{array}$ & $\begin{array}{c}\text { Diameter } \\
{[\mathrm{mm}]}\end{array}$ & $\begin{array}{c}\text { Height } \\
{[\mathrm{mm}]}\end{array}$ & $\begin{array}{c}\text { Dry } \\
\text { weight } \\
{[\mathrm{g}]}\end{array}$ \\
\hline B3 & 484 & 2.65 & 19.4533 & 67.5345 & 38.0 & 75.6 & 173.2376 \\
C2 & 190 & 2.66 & 17.1784 & 69.6948 & 38.4 & 75.9 & 184.7513 \\
\hline
\end{tabular}

\subsection{Continuity test}

This preliminary phase was aimed at verifying that the system was fully saturated prior to initiating the test. Air can remain entrapped (1) in the sample pore-space if the saturation procedure is not effective and (2) between the sample and its boundaries (pedestal, top cap, and membrane) during the installation of sample and probe.

To this end, the water/oil interface was isolated by closing valve 1 (Figure 8 ). Then, the water pressure at the pedestal was increased to about $100 \mathrm{kPa}$. The pressure measured by the hydrophilic probe WP and the pressure transducer PT on the oil line was then monitored. If the system was fully saturated, the hydrophilic probe and the pressure transducer PT should have recorded the same change in pressure imposed at the base of the sample with negligible time lag.

Figure 11a shows the continuity test for the first sample B3. A water pressure of $105 \mathrm{kPa}$ was imposed at the pedestal and maintained constant over time. The pressure measured by the probe WP and the pressure transducer PT initially increased by a significantly smaller amount (up to about $30 \mathrm{kPa}$ ). This was associated with the presence of large amounts of air, likely entering the gap between the sample and the membrane when the membrane was cut laterally to insert the hydrophilic probe. The air was then flushed by opening valve B at the top of the cell (Figure 8) at around $4500 \mathrm{~min}$. The air flushing could remove most but not all the air present in the system. However, the pressure recorded by the probe and the pressure transducer on the oil line started recording an increasing pressure after the air flushing likely because of the dissolution of air cavities present in the system. Eventually both transducers attained the same pressure imposed at the base of the sample and this was taken as an indication that the system achieved full saturation. Similar response was observed for sample $\mathrm{C} 2$ as shown in Figure $11 \mathrm{~b}$. 

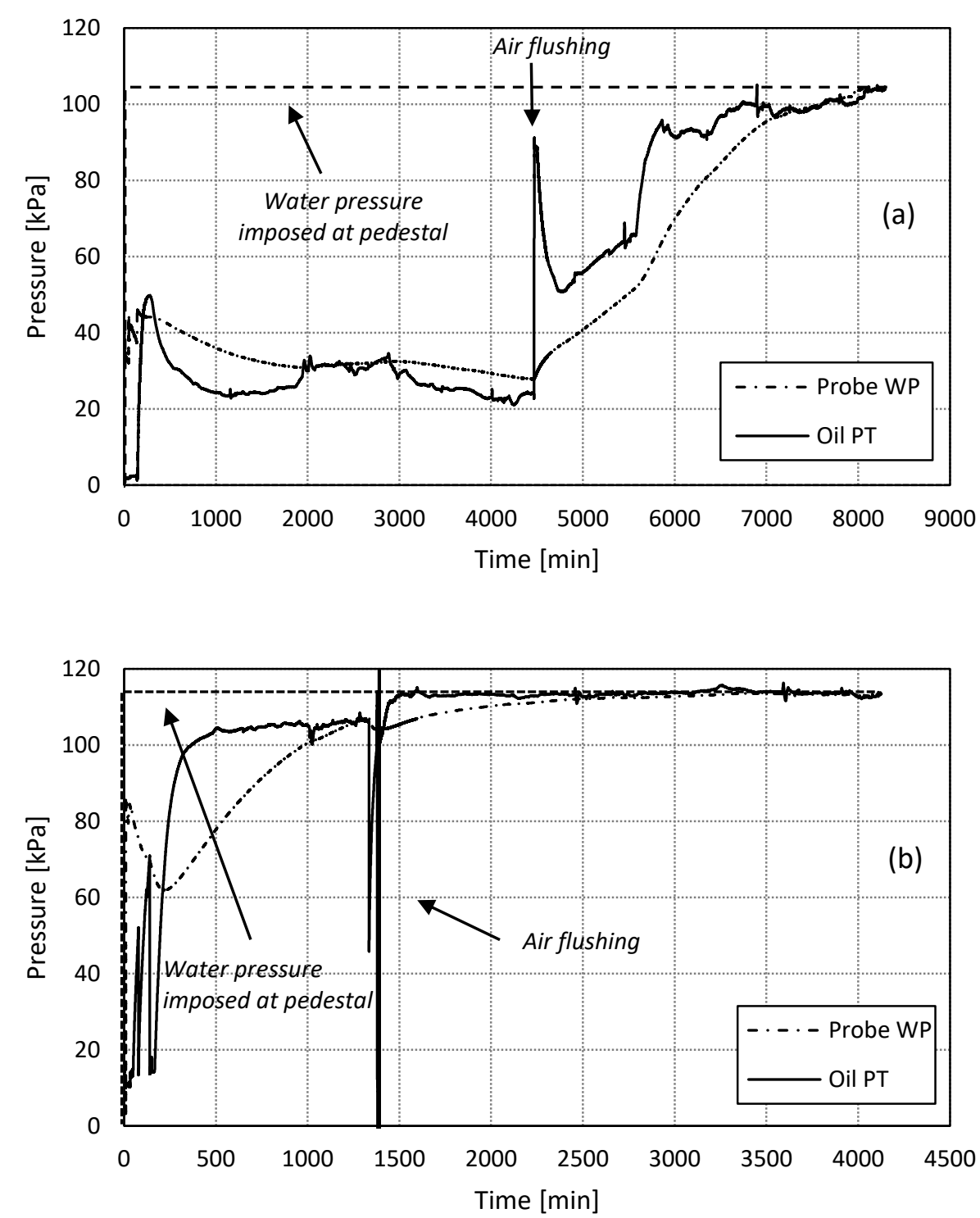

Figure 11. Water pressure measured by probe (Probe WP) and oil pressure measured by pressure transducer on oil line (Oil PT) during continuity tests. (a) Sample B3. (b) Sample C2

\subsection{Pore-water pressure measurement: sample B3}

Following the continuity test, the water pressure imposed at the base was maintained constant and the oil pressure at the top of the sample was increased according to the sequence detailed in Table 3. The capillary pressure $\mathrm{P}_{\mathrm{c}}$ imposed at the boundary defined by Equation (1) was therefore increased.

The confining pressure $\left(\mathrm{P}_{\text {confining }}\right)$ was initially imposed at $500 \mathrm{kPa}$ and increased to $650 \mathrm{kPa}$ in step 3 . This guaranteed that the confining pressure was always higher than the pore-oil pressure.

The oil pressure imposed (oil pressure, $\mathrm{P}_{\mathrm{o}}$ ) and the pore-water pressure measured by the hydrophilic probe measured in the first step associated with a capillary pressure imposed at the boundary equal to $145 \mathrm{kPa}$ is shown in Figure 12. As the oil pressure was imposed, the pore-water pressure measured by the hydrophilic probe initially reached the same pressure imposed to the sample through the oil line $(\sim 250 \mathrm{kPa})$ despite the water pressure imposed at its base was still $105 \mathrm{kPa}$. This is because the water drainage at the base of the sample does not occur instantaneously and the pore-fluid initially responds as if there was an impermeable boundary at the base of the sample. With time, water drained towards the base of the sample and the initial excess of pore-water pressure measured by the hydrophilic probe dissipated and the pore-water tended to level 
off to a value of $\sim 125 \mathrm{kPa}$ close to the pore-water pressure imposed at the base of the sample ( 105 kPa). At equilibrium, the probe could therefore measure essentially the same water pressure imposed at the bottom despite a much higher oil pressure in the pore-space. This proves that the probe achieved its goal, i.e. establish continuity with the pore-water while preventing the ingress of oil in the probe.

Table 3. Pressures imposed in the test on sample $B 3$, oil pressure $P_{o}$ imposed at the top, water pressure $P_{w}$ imposed at the bottom, capillary pressure $P_{c}$, and confining pressure $P_{\text {confining }}$

\begin{tabular}{ccccc}
\hline Step & $\mathrm{P}_{\mathrm{w}}[\mathrm{kPa}]$ & $\mathrm{P}_{\mathrm{o}}[\mathrm{kPa}]$ & $\mathrm{P}_{\mathrm{c}}[\mathrm{kPa}]$ & $\mathrm{P}_{\text {confining }}[\mathrm{kPa}]$ \\
\hline 1 & 105 & 250 & 145 & 500 \\
2 & 105 & 350 & 245 & 500 \\
3 & 105 & 450 & 345 & 650 \\
4 & 105 & 600 & 545 & 650 \\
\hline
\end{tabular}

The process of dissipation of the excess pore-water pressure was accompanied by a water volume flowing out of the sample, which was measured by the pressure/volume controller GDS1. This water volume was replaced by volume of oil entering from the top end of the sample. Because the sample was initially fully saturated, and assuming that the pore volume, $\mathrm{V}_{\mathrm{p}}$, of the sandstone sample remained constant and equal to the initial value (Table 2), it was possible to determine the water degree of saturation of the sample $\left(\mathrm{S}_{\mathrm{rw}}\right)$ :

$$
S_{r w}=\left(V_{w} / V_{p}\right) * 100
$$

where $V_{w}$ is the water volume in the sample. The volume of oil, $V_{o}$, injected into the sample, was zero initially and increased as water drained at the bottom of the sample. At the end of the drainage process following the application of a capillary pressure of $145 \mathrm{kPa}$, water degree of saturation attained the relatively low value of $\mathrm{S}_{\mathrm{rw}}=22 \%$ (Figure 13), indicating that a significant amount of water drained out of the pore-space.

The results of the following three steps where capillary pressure at the boundaries was increased to 245, 345, and $545 \mathrm{kPa}$ respectively (Table 3) are shown in Figure 14. As oil pressure was increased at the top of the sample, the water pressure recorded by the hydrophilic probe increased only slightly, possibly because the water degree of saturation was very low at the start of the second step $\left(S_{\mathrm{rw}}=22 \%\right)$, i.e. the degree of saturation was approaching the condition where water becomes discontinuous in the pore-space. In all three steps, the hydrophilic probe kept measuring a pressure very close to the one imposed at the bottom of the sample. Eventually, oil pressure reached $545 \mathrm{kPa}$ while the hydrophilic probe was still measuring a pressure about 125 $\mathrm{kPa}$.

Again, this can be taken as a validation of the probe, in the sense that it was successful in measuring only the pressure of the water (wetting fluid) despite the presence of the oil (non-wetting fluid) in the pore space at much higher pressure. 


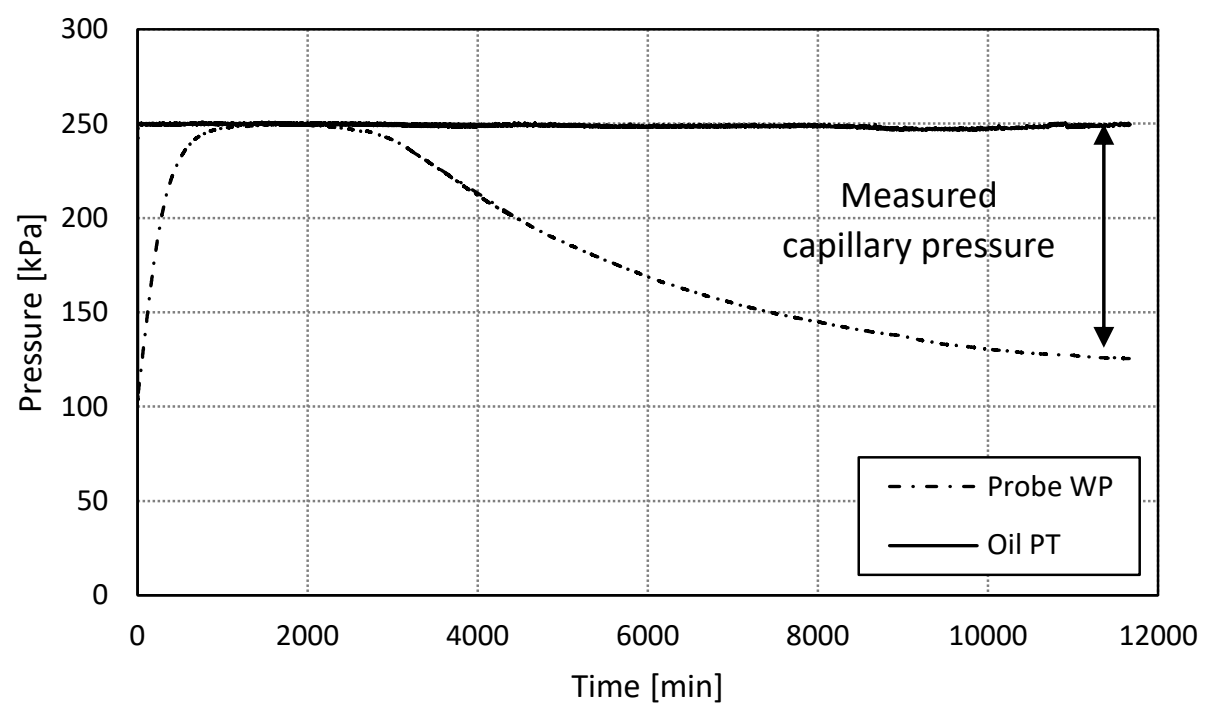

Figure 12. Sample B3: Imposed oil pressure (PT) and measured pore-water pressure (WP) associated with capillary pressure increased at the boundaries to $150 \mathrm{kPa}$

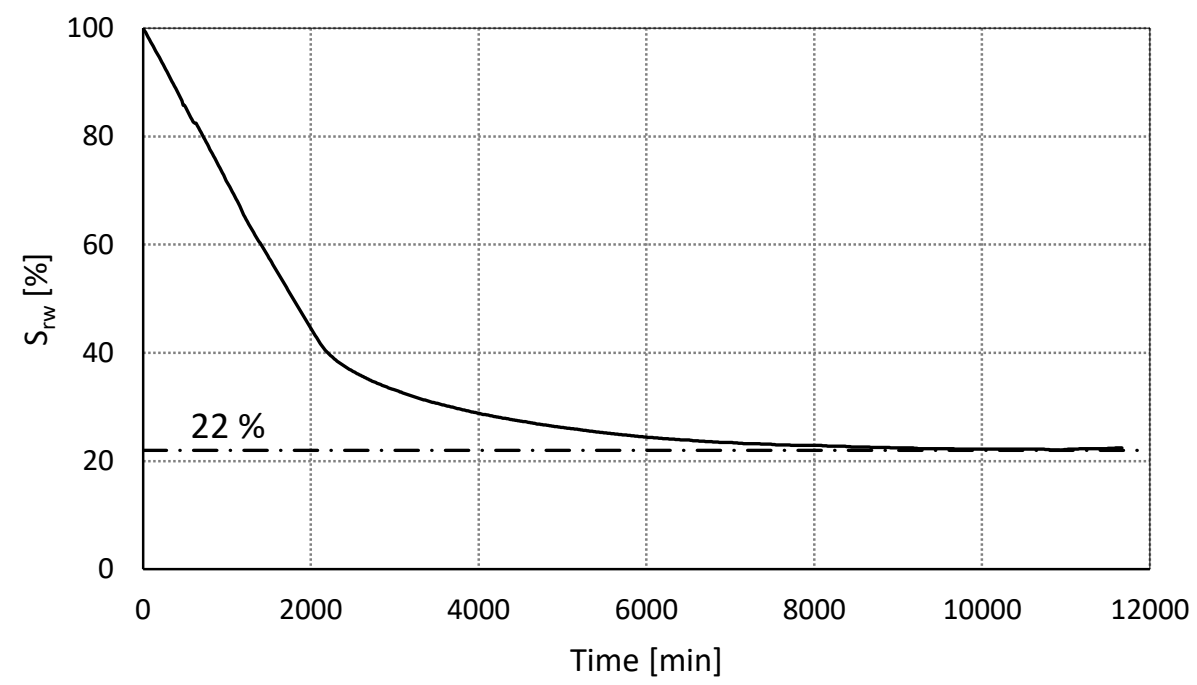



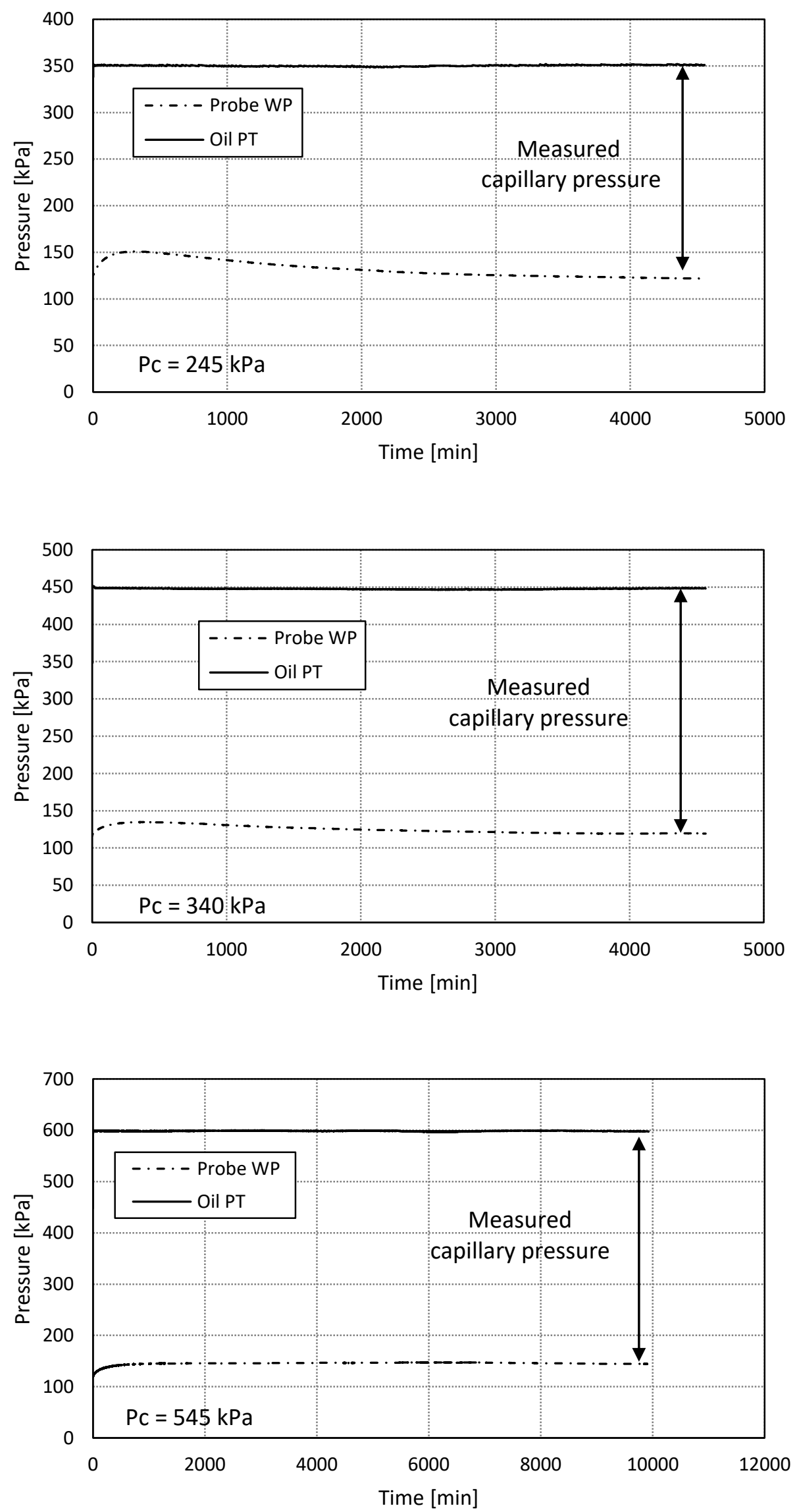

(c) 


\subsection{Pore-water pressure measurement: sample C2}

A second test was performed on a sample of sandstone having similar porosity and permeability as sample B3 (Table 2). It was therefore expected to have similar water retention behaviour, i.e. the relationship between the water degree of saturation versus the capillary pressure.

For the case of sample B3, a capillary pressure of about $150 \mathrm{kPa}$ was imposed as a first step, which brought the degree of saturation to a very low value $(\sim 22 \%)$, close to the state where water becomes discontinuous in the pore space.

The objective of the test on sample $\mathrm{C} 2$ was to explore the behaviour of the hydrophilic probe at higher degrees of saturation. To this end, this sample was initially subjected to a significantly smaller increase capillary pressure, i.e. $20 \mathrm{kPa}$ as shown in Table 4.

Table 4. Pressures imposed in the test on sample $C 2$, oil pressure $P_{o}$ imposed at the top, water pressure $P_{w}$ imposed at the bottom, capillary pressure $P_{c}$, and confining pressure $P_{\text {confining }}$

\begin{tabular}{ccccc}
\hline Step & $\mathrm{P}_{\mathrm{w}}[\mathrm{kPa}]$ & $\mathrm{P}_{\mathrm{o}}[\mathrm{kPa}]$ & $\mathrm{P}_{\mathrm{c}}[\mathrm{kPa}]$ & $\mathrm{P}_{\text {confining }}[\mathrm{kPa}]$ \\
\hline 1 & 112 & 132 & 20 & 500 \\
2 & 142 & 132 & -10 & 500 \\
3 & 112 & 212 & 100 & 500 \\
\hline
\end{tabular}

The evolution of the water pressure measured by the hydrophilic probe once the oil pressure at the top of the sample was set to $132 \mathrm{kPa}$ while maintaining a water pressure at the base of the sample equal to $112 \mathrm{kPa}$ is shown in Figure 15.

Similarly to the response observed in the first step of the test on sample B3 (Figure 12), the water pressure recorded by the hydrophilic probe (WP) initially increased up to the value of the oil pressure $(\sim 132 \mathrm{kPa})$, despite the lower water pressure imposed at its base $(112 \mathrm{kPa})$. As a consequence of the water pressure differential between the water pressure induced in the sample and the water pressure at its (lower) boundary, water drained towards the base of the sample and the degree of saturation started to decrease accordingly (Figure 16).

After around 10,000 min, the water pressure inside the sample started to decrease in a way similar to what observed for sample B3. However, the decay in water pressure was very slow. After about 55,500 min ( 40 days), the difference between the imposed oil pressure and the water pressure measured by the probe was only about $10 \mathrm{kPa}$ (Figure 15) against a target of $20 \mathrm{kPa}$ capillary pressure. The equalisation process was not yet completed even if the degree of saturation seemed to approach a plateau. Extrapolation of the water degree of saturation versus time curve suggested that equilibrium at $S_{\mathrm{rw}}=46 \%$ would have been achieved after about 70 days $(100,000 \mathrm{~min})$ and this could possibly explain why the water pressure recorded by the probe had not yet reached its equilibrium value.

Another explanation was the possible loss of water continuity occurred between the sample and the pedestal where water pressure is imposed by the controller. To inspect the continuity of the water phase, water pressure at the pedestal was increased to a value greater than the oil pressure imposed at the top (Figure 17a). Water then flowed into the sample as shown by the increase in degree of saturation, which reached the value of $\mathrm{S}_{\mathrm{rw}}=87 \%$ (Figure 17b.). This showed that the pore-water was effectively controlled through the water pressure line at the pedestal. 


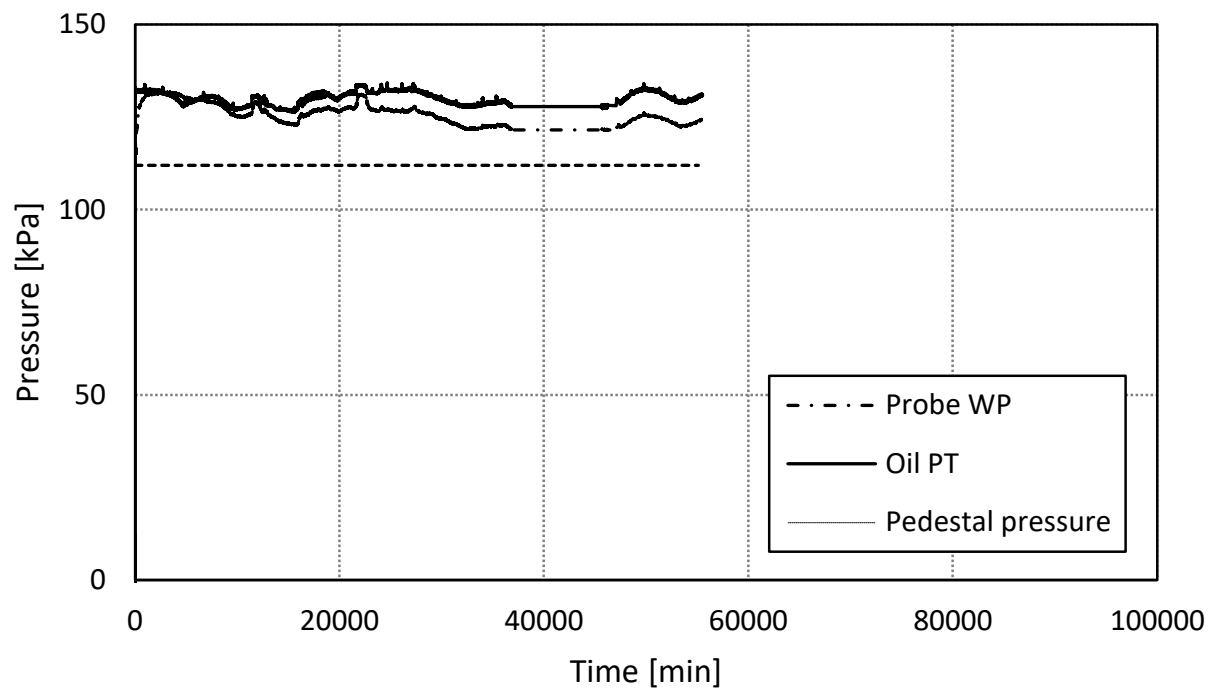

403

404 Figure 15. Sample C2. Imposed oil pressure (PT) and measured pore-water pressure (WP) associated with capillary 405 pressure increased to $20 \mathrm{kPa}$ at the boundaries (Step 1)

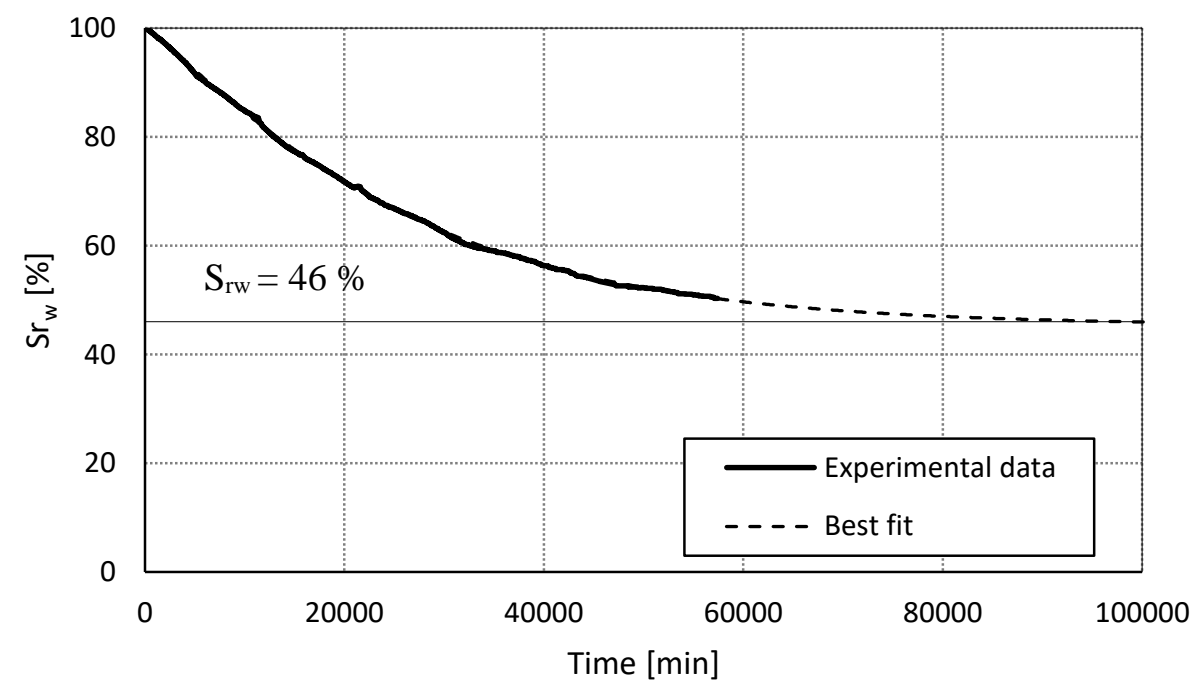

406

407 Figure 16. Sample C2: variation of the degree of saturation related to water drainage during step $1\left(P_{c}=20 \mathrm{kPa}\right)$ 

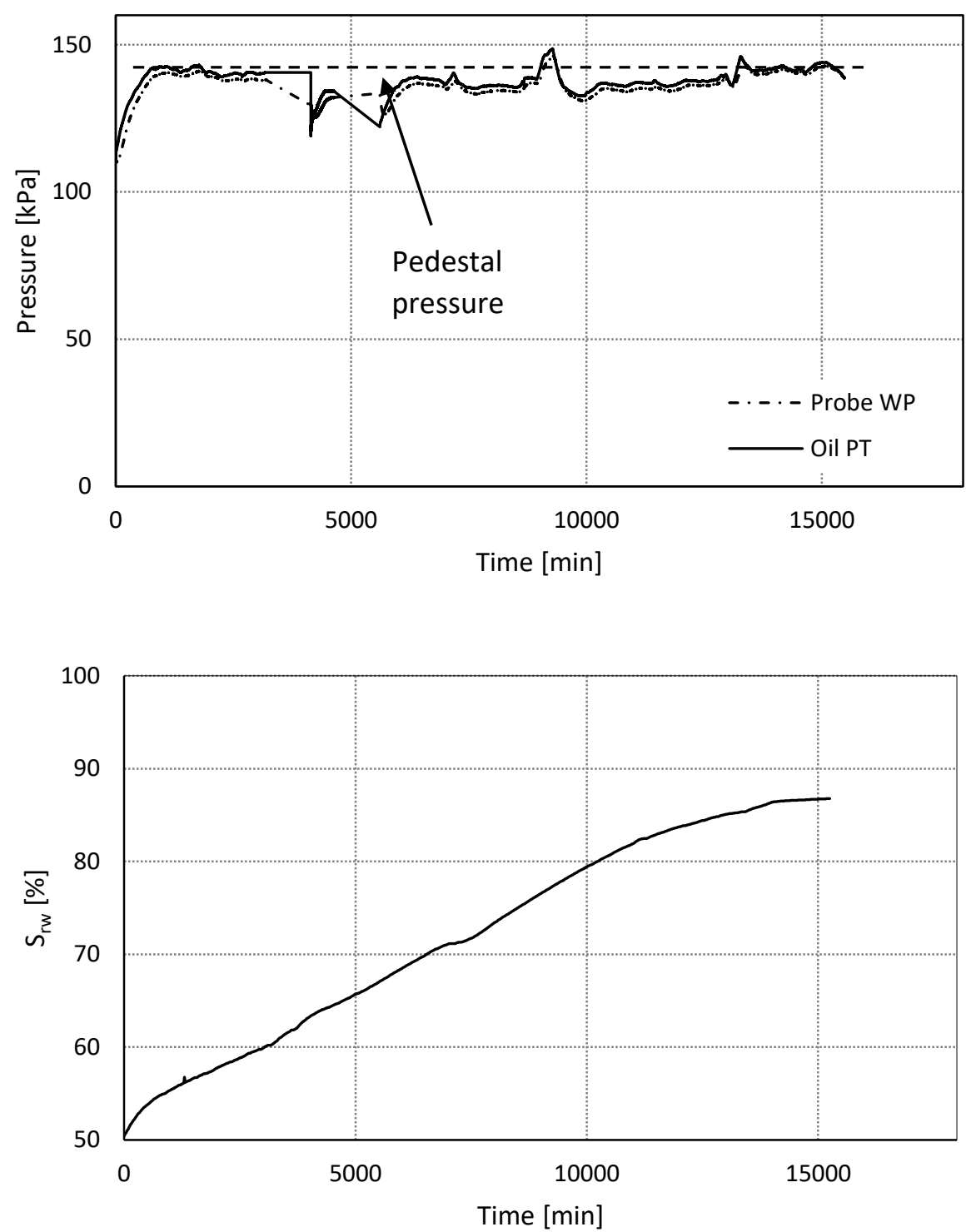

Figure 17. Sample C2. (a) Imposed oil pressure (PT) and measured pore-water pressure (WP) associated with capillary pressure decreased to $-10 \mathrm{kPa}$ at the boundaries (Step 2). (b) Variation of the water degree of saturation

Capillary pressure was then increased to $100 \mathrm{kPa}$ (Step 3) inducing again water drainage (Figure 18). The water pressure measured by the probe initially increase to the same value of the oil pressure imposed at the top of the sample $(212 \mathrm{kPa})$. The excess pore-water pressure then started to decrease to equalise with the water pressure imposed ta the bottom of the sample $(112 \mathrm{kPa})$ and the water degree of saturation decreased accordingly.

However, after 5000 minutes from the start of this step, the drainage almost instantaneously stopped. This was taken as an indication that the continuity between the water in the sample and the water in the pedestal was lost due to the very low degree of saturation attained by the sample. It was assumed that a thin layer of oil covered completely the surface of the porous stone. The loss of continuity also had an effect on the water pressure measured by the hydrophilic probe. The water phase in the core plug was no longer in communication with the water in the pedestal, i.e. the water pressure imposed on the pedestal was no longer transferred to the sample. As a result, the pressure measured by the probe started to increase again and tended to equilibrate with the oil pressure (Figure 18). This equilibrium did not mean that the probe was measuring the oil pressure; the hydrophilic probe was measuring the water pressure in equilibrium with the oil pressure within the sample. 

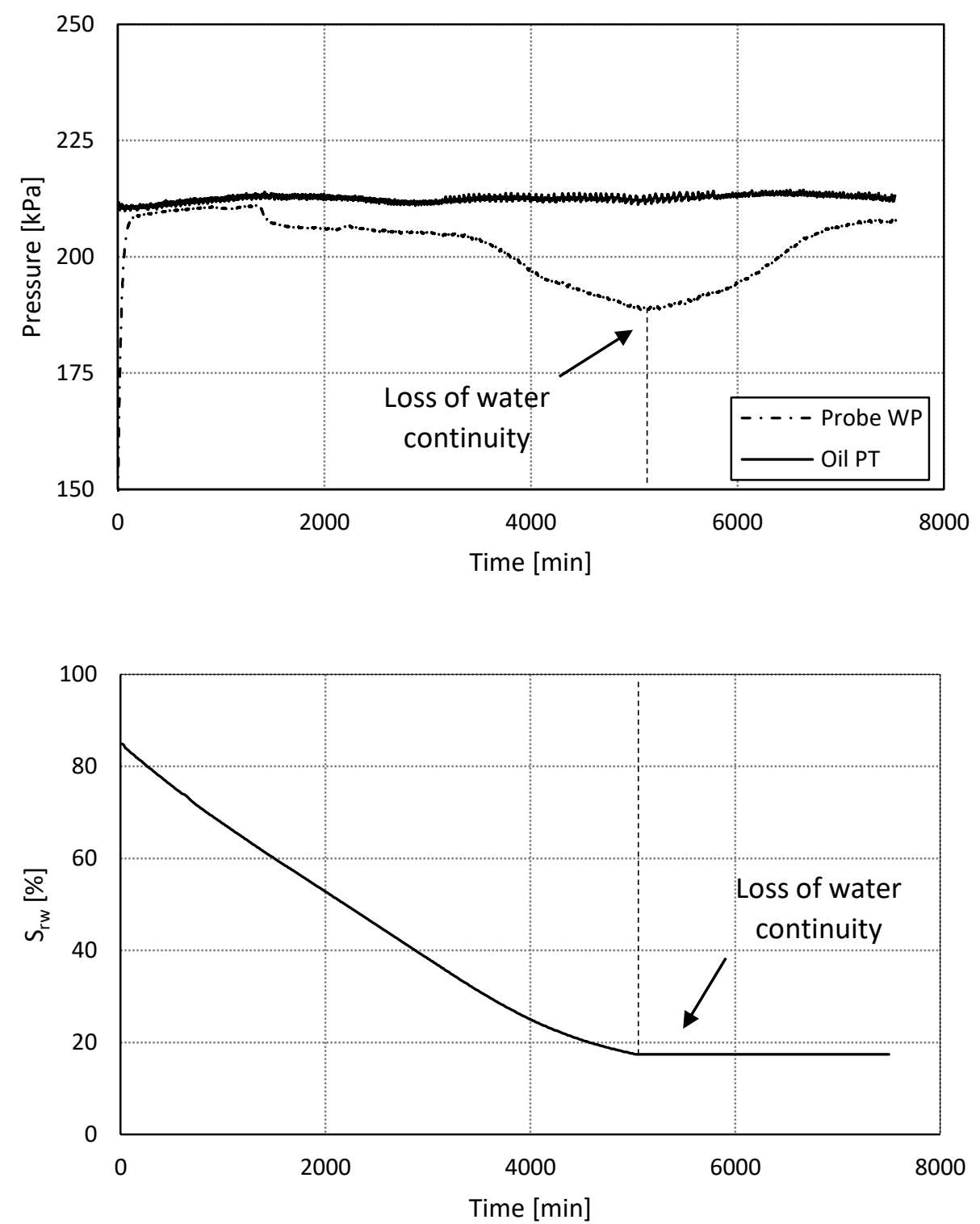

Figure 18. Sample C2. (a) Imposed oil pressure (PT) and measured pore-water pressure (WP) associated with capillary pressure increased to $100 \mathrm{kPa}$ at the boundaries (Step 3) (b) Variation of the water degree of saturation

\section{CONCLUSIONS}

This paper has presented and validated a new probe for measuring the pore-water pressure in hydrocarbon reservoirs. The probe offers the possibility of measuring the pore-water pressure in porous rocks independently of the oil pressure for the case where oil and water are both present in the porous space. In principle a single measurement of pore water pressure in a single drilling would allow determining the depth of the Free Water Level, in contrast to the current practice of drilling multiple wells for the case where water is not intercepted by the well. In this way, it could be possible to improve the appraisal process guiding drilling campaigns, saving time, and reducing both, costs and environmental impact of hydrocarbon search.

The probe concept consists of a brass shroud, incorporating a porous ceramic interface saturated with water, fitted onto a commercial pressure transducer. The ability of the saturated porous ceramic to create a proper barrier to the oil phase was preliminary verified in a modified bubbling pressure device. 
The probe was then tested on sandstone samples where water pressure was controlled at the bottom, oil pressure at the top and the probe was installed laterally at the sample mid height. At first, a water pressure was imposed to the sample, which ensured that the sample was initially fully saturated with water. Then, oil pressure at the top of the sample was increased while maintaining the water pressure at the bottom constant. Oil then penetrated into the sample and water degree of saturation decreased to values lower than unity. The aim of this test was to verify that, after a transient period, the probe could successfully equilibrate with the water pressure imposed at the bottom of the sample.

In the test performed on the first sandstone core plug (B3) the oil pressure was increased in four steps up to $545 \mathrm{kPa}$ while the water pressure imposed at the bottom was kept at $105 \mathrm{kPa}$. In all steps the pressure recorded by the probe initially increased and then tended to reduce as water drainage took place. At equilibrium, the pressure measured by the probe was essentially equal to the pressure imposed at the pedestal $(105 \mathrm{kPa})$.

In the test performed on the second sandstone core plug (C2), the equilibration processes were significantly slower. When imposing a capillary pressure of $100 \mathrm{kPa}$, again the pressure recorded by the probe initially increased and then tended to reduce as water drainage took place. However, water drainage from the bottom of the sample stopped abruptly when the water degree of saturation attained a very low value, which indicated loss of continuity between the water in the sample and the water in the pedestal, where the drainage was taking place. This was associated with the water phase becoming discontinuous in the sample at very low water degree of saturation. At this point, the probe started measuring the water pressure in equilibrium with the oil pressure within the sample.

The mock-up tests on sandstone core plugs B3 and C2 have shown that the prototype probe designed can successfully measure the water pressure in samples saturated with water and oil, as long as there is continuity within the water phase. In fact, the hydraulic continuity between the water in the ceramic interphase and the water below the FWL is the only limitation identified for using this probe under laboratory conditions. The presence of discontinuities inside the probe, i.e. poor saturation of the ceramic interphase, air trapped, accidental occurrence of cavitation during the probe installation (when the probe can be in contact with the air), or presence of hydraulic discontinuities in the sample's depth, can compromise the measure, as happened in the last part of test on core plug C2 (Figure 18). However, under laboratory conditions these later limitations related to the water discontinuity inside the probe are manageable and controlled. Thus, the obtained results suggest this technology can be used in all oil reservoirs where there is continuous intrusion of wetting fluid (water) into the pore space occupied by the non-wetting fluid (oil). The present study, providing the proof-ofconcept for the technology investigated, can now be moved to the next readiness level.

\section{ACKNOWLEDGEMENT}

This study was financed by the Oil and Gas Innovation Centre (OGIC) with the support of Core Specialists and Hydrophilic AS. The authors wish to acknowledge the contribution of Derek McNee, technician of the Geomechanics Laboratory at the University of Strathclyde to the retrofitting of the triaxial cell; Dr Brunella Balzano for her precious help to capture the water menisci, Trond Rolfsvåg (Hydrophilic AS), Craig Lindsay and Richard Ashcroft (Core specialists) for the fruitful technical discussions throughout the project.

\section{REFERENCES}

Aminzadeh, F. and Dasgupta, S. N. (2013) 'Chapter 2 - Fundamentals of Petroleum Geology', in Aminzadeh, F. and Dasgupta, S. N. B. T.-D. in P. S. (eds) Geophysics for Petroleum Engineers. Elsevier, pp. 15-36. doi: https://doi.org/10.1016/B978-0-444-50662-7.00002-0.

Amyx, J. W., Bass, M. B. J. and Whiting, R. L. (1960) Petroleum Reservoir Engineering: Physical Properties. McGraw-Hill Book Company Inc. 
Andersen, P. et al. (2019) 'Simulation interpretation of capillary pressure and relative permeability from waterflooding laboratory experiments in preferentially oil-wet porous media', in EAGE: IOR 2019 - 20th European Symposium on Improved Oil Recovery. doi: 10.2118/197065-pa.

Arps, J. J. (1964) 'Engineering Concepts Useful in Oil Finding', American Association of Petroleum Geologists Bulletin, 48(2), pp. 157-165. doi: 10.1306/bc743bd9-16be-11d7-8645000102c1865d.

Berg, R. R. (1975) 'Capillary Pressures in Stratigraphic Traps', The American Association of Petroleum Geologists Bulletin, 59(6), pp. 939-956. doi: 10.1306/83d91ef7-16c7-11d7-8645000102c1865d.

Biddle, Kevin, T. and Wielchowsky, C. C. (1994) 'Hydrocarbon traps', AAPG Memoir, 60, pp. $219-235$. Available at: https://www.researchgate.net/publication/264738948.

Busby, R. D., Lenhard, R. J. and Rolston, D. E. (1995) 'An Investigation of Saturation-Capillary Pressure Relations in Two- and Three-Fluid Systems for Several NAPLS in Different Porous Media', Groundwater, pp. 570-578. doi: 10.1111/j.1745-6584.1995.tb00312.x.

Cui, Y. J., Delage, P. and Alzoghbi, P. (2003) 'Retention and transport of a hydrocarbon in a silt', Géotechnique, 53(1), pp. 83-92. doi: 10.1680/geot.53.1.83.37248.

Elshahawi, H., Fathy, K. and Hiekal, S. (1999) 'Capillary pressure and rock wettability effects on wireline formation tester measurements', in Proceedings of the SPE Annual Technical Conference and Exhibition. Texas: SPE, pp. 499-514. doi: 10.2523/56712-ms.

De Gennaro, V. et al. (2003) 'Time-dependent behaviour of oil reservoir chalk: A multiphase approach', Soils and Foundations, pp. 131-147. doi: 10.3208/sandf.43.4_131.

Niculescu, B. M. and Ciupercă, C. L. (2019) 'Identification of fluid contacts by using formation pressure data and geophysical well logs', in 19th International Multidisciplinary Scientific GeoConference, SGEM, pp. 897-908. doi: 10.5593/sgem2019/1.2/S06.114.

Rolfsvåg, T. A. et al. (2019) 'Water Pressure Measurement Inside a Hydrocarbon Column Please', in SPE Norway One Day Seminar. doi: 10.1017/CBO9781107415324.004.

Shi, S., Belhaj, H. and Bera, A. (2018) 'Capillary pressure and relative permeability correlations for transition zones of carbonate reservoirs', Journal of Petroleum Exploration and Production Technology. Springer Berlin Heidelberg, 8(3), pp. 767-784. doi: 10.1007/s13202-017-0384-5.

Steffy, D. A., Barry, D. A. and Johnston, C. D. (1997) 'Influence of antecedent moisture content on residual LNAPL saturation', Soil and Sediment Contamination, 6(2), pp. 113-147. doi: $10.1080 / 15320389709383552$.

Tarantino, A. (2004) 'Panel lecture: Direct measurement of soil water tension', in Jucá, DeCampos, and Marinho (eds) Proc. 3nd Int. Conf. on Unsaturated Soils, pp. 1: 319-324.

Teige, G. M. G. et al. (2005) 'Capillary resistance and trapping of hydrocarbons: A laboratory experiment', Petroleum Geoscience, 11, pp. 125-129. doi: 10.1144/1354-079304-609.

Teige, G. M. G. et al. (2006) 'Relative permeability to wetting-phase water in oil reservoirs', Journal of Geophysical Research, 111. doi: 10.1029/2005JB003804.

Underschultz, J. (2005) 'Pressure distribution in a reservoir affected by capillarity and hydrodynamic drive: Griffin Field, North West Shelf, Australia', Geofluids, 5(3), pp. 221-235. doi: 10.1111/j.14688123.2005.00112.x.

Vavra, C. L., Kaldi, J. G. and Sneider, R. M. (1992) 'Geological applications of capillary pressure: a review', American Association of Petroleum Geologists Bulletin, 76(6), pp. 840-850. doi: 10.1306/bdff88f8-1718$11 \mathrm{~d} 7-8645000102 \mathrm{c} 1865 \mathrm{~d}$. 